Esta revista forma parte del acervo de la Biblioteca Jurídica Virtual del Instituto de Investigaciones Jurídicas de la UNAM

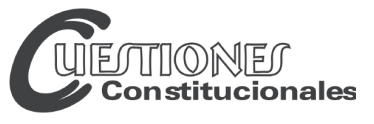

Revista Mexicana de Derecho Constitucional

Núm. 27, julio-diciembre 2012

\title{
UNA APROXIMACIÓN AL IUSCULTURALISMO DE PETER HÄBERLE
}

\author{
AN APPROACH TO THE IUSCULTURALISM \\ OF PETER HÄBERLE
}

\section{Pedro Daniel GonzÁLEZ Rivas MARTíneZ*}

\begin{abstract}
RESUMEN: Uno de los elementos más difíciles de desarrollar para todo estudioso de los fenómenos constitucionales es un marco teórico académicamente sólido. Sin duda la obra de Peter Häberle se encuentra sustentada en uno, aunque, por sus rasgos, su novedad y su distancia respecto de los paradigmas hasta hoy dominantes, resulta difícil de asir. El presente texto es producto de un trabajo en el que se buscó extraer el modelo teórico generado y utilizado por Häberle a lo largo de su vasta obra académica. El contenido se compone de enunciados que pretenden explicitar, de manera profunda, clara, sintética y actualizada, las premisas fundamentales del modelo teórico haberleano. La finalidad es que todo estudioso de la teoría constitucional que necesite de un marco jurídico tenga acceso al esquema de este autor. Para ello se presenta, primeramente, la postura epistemológica del autor. A continuación el lector encontrará un catálogo de elementos teóricos y técnicos que pueden ser utilizados como enunciados básicos para el desarrollo de cualquier investigación académica en el ámbito de la teoría constitucional. En términos amplios, este trabajo persigue contestar a las siguientes cuestiones respecto del modelo teórico de Häberle: ¿qué conoce? Y ¿cómo lo conoce?
\end{abstract}

Palabras clave: teoría constitucional como ciencia de la cultura, iusculturalismo, el tipo Estado constitucional, la Constitución como cultura, marco teórico de Peter Häberle.
ABSTRACT: One of the most difficult elements to develop for any student of the constitutional phenomena is an academically solid theoretical frame. Without a doubt the work of Peter Häberle is sustained on one, although, by its characteristics, novelty and distance with respect to the currently dominant paradigms, is difficult to grasp. The present text is product of a work that aims to extract the theoretical model generated and used by Häberle throughout his vast academic work. The content is made up of statements that try to specify in a deep, clear, synthetic and up-to-date way, the fundamental premises of the haberlean theoretical model. The purpose is that every student of the constitutional theory that needs a juridic frame has access to the scheme of this author. To accomplish that, the epistemological position of the author is presented first. Next, the reader will find a catalogue of theoretical and technical elements that can be used as statements and basic methods for the development of any academic investigation in the scope of constitutional theory. In broad terms, this work pursues to answer the following questions with respect to Häberle's theoretical model: What does it know? And how does it know?

Descriptors: constitutional theory as a cultural science, iusculturalism, the constitutional State type, the Constitution as culture, theoretical frame of Peter Häberle.

* Doctorando por la Facultad de Derecho de la Universidad Autónoma de Querétaro. 
"...la justicia es la verdad del derecho"1

\section{LOS FOROS ABIERTOS DE LA VERDAD}

A lo largo de su extensa obra, Peter Häberle estudia los problemas constitucionales con una visión antropológica ${ }^{2}$ y propone un modelo teórico de gran abstracción al que denomina "Teoría de la Constitución como ciencia de la cultura". Este enfoque pretende enriquecer o superar la concepción tradicional que se tiene de la Constitución como objeto de estudio. Esa concepción tradicional observa a la Constitución como impulso y límite, como norma y tarea, como limitación y racionalización, como proceso público. Para la teoría constitucional como ciencia de la cultura, "las normas constitucionales surgen y se entienden como procesos culturales y se explican a través de los textos y los contextos". ${ }^{3}$ Lo puramente jurídico no abarca todo lo que la Constitución es. La Constitución de un pueblo es la imagen de una sociedad concebida como idónea en un tiempo y lugar determinados. Esa imagen es aquello que esa sociedad aspira a ser, la propia comunidad se crea esa imagen a seguir; acuerda perseguirla no sólo como un club social, sino como una meta seria, tan seria que su poder soberano es depositado y utilizado con ese objetivo.

El enfoque de la ciencia cultural distingue lo individual de cada Estado constitucional de aquello que es común a todos ellos o a su mayoría; con esto último conforma un "arquetipo". El proceso comienza con el estudio particular de las culturas constitucionales democráticas y concluye, en su nivel más general, con la identificación de los elementos compartidos por la

1 Háberle, Peter, Verdad y Estado constitucional, trad. de Guillermo Mañón Garibay, México, UNAM, 2006, p. 151.

2 Häberle, Peter, Pluralismo y Constitución, trad. de Emilio Mikunda-Franco, España, Tecnos, 2002, p. 104.

3 Häberle, Peter y Kotzur, Markus, De la soberanía al derecho común: palabras clave para un diálogo europeo-latinoamericano, trad. de Héctor Fix-Fierro, México, UNAM, Instituto de Investigaciones Jurídicas, 2003, p. 5. Donde se puede encontrar un desarrollo profundo del tema. También conviene remitirse al apartado denominado "La teoría de la Constitución como ciencia jurídica de los textos y la cultura" en: Häberle, Peter, El Estado constitucional, trad. de Héctor Fix-Fierro, México, UNAM, Instituto de Investigaciones Jurídicas, 2003; al igual que los apartados denominados: "La Constitución como cultura" y "La sociedad abierta de los intérpretes constitucionales" del presente texto. 
mayoría de ellas. El modelo resultante puede utilizarse como criterio para determinar si un proyecto o realidad social califica como Estado constitucional, social, democrático y cultural de derecho.

El enfoque teórico häberleano llama a utilizar no sólo las herramientas de la jurisprudencia, sino también las de todas las ciencias y artes que conforman "la gran antropología" como ciencia y arte de la cultura humana. Una visión móvil y pluridimensional que admite no sólo el disentimiento sino, incluso, la oposición como medios de enriquecimiento. De esta manera, el objeto de estudio se vuelve, aparentemente, "nebuloso" o difuso desde una visión formalista; aunque, en realidad, el resultado del aporte de todos los aspectos parciales proporcionados por cada perspectiva teórica es la conformación más exacta del mismo; especialmente si se entiende la Constitución como una estructura cultural multidimensional, como es el caso. Para nuestro autor, una visión más restrictiva de la Constitución resulta reduccionista e ingenua; especialmente si se tiene en cuenta que la perspectiva cultural de la Constitución permite ver, por una parte, la cultura constitucional cristalizada en los textos respectivos dándoles fondo, cimentación y suelo cultural ${ }^{4}$, y por la otra, haciendo "el ámbito material y funcional 'cultura' el terreno desde el cual surgen"5 los elementos de cada Constitución particular y del arquetipo Estado constitucional.

Häberle propone un modelo epistemológico a ser adoptado, tanto por los estudiosos de la fenomenología constitucional, como por los participantes del ámbito político. ${ }^{6}$ Su propuesta pretende ser un paradigma en todos los sentidos posibles del término: una cosmovisión, una matriz con fuerza descriptiva y disciplinaria. Con absoluta congruencia, él mismo utiliza esta perspectiva teórica; como científico, la postula y la pone en práctica a lo largo de toda su obra. Este enfoque tiene su fundamento último en lo que llama la verdad "plural", concepción basada en el respeto a la dignidad humana de cada individuo. Con el reconocimiento de que cada ser humano tiene, no sólo su propia verdad, también distintos regímenes de verdad.

4 Valadés, Diego (comp.), Conversaciones académicas con Peter Häberle, México, UNAM, Instituto de Investigaciones Jurídicas, 2006, p. 44 (síntesis). Nuestro autor presupone el entendimiento de la idea de que el intérprete es quien asigna significado al texto. Para que los textos constitucionales adquieran sentido el elemento determinante es la cultura de sus intérpretes.

5 Häberle, Peter, La libertad fundamental en el Estado constitucional, trad. de Carlos Ramos y Jürgen Saligmann. Perú, Universidad Católica del Perú, 1997, p. 304.

6 Häberle, Peter, op. cit., nota 2, p. 163. 
Así, es razonable que Häberle contemple la interpretación constitucional como algo constante y plenamente abierto, tanto con respecto a los partícipes en el proceso, como en lo relativo a los regímenes de verdad admisibles como tales. Postular una visión cerrada sería considerado, además de poco realista, autoritario, y negaría el derecho a la opinión personal originaria, deslegitimando su expresión. Es por ello que nuestro autor postula, en todos los niveles de discurso y en todo ámbito, lo que denomina el Principio Metodológico del "pensamiento de lo posible", que significa pensar en y desde otras alternativas; máxima relativa a las realidades, necesidades y posibilidades en el campo gravitacional del Estado constitucional. ${ }^{8}$ Para Häberle "el Estado constitucional se contrapone a cualquier tipo de Estado totalitario" del tinte ideológico que sea; se opone al sostenimiento "de toda verdad absoluta y a cualquier monopolio de información, así como a la imposición de una ideología totalitaria". "Rechaza, por tanto, todo lo que podemos caracterizar con la palabra fundamentalismo". ${ }^{11}$ Este modelo no da cabida a verdad definitiva o absoluta, pues se encuentra en la constante búsqueda de la misma. Häberle intenta concebir al Estado constitucional y a la disciplina que lo estudia y lo construye en lo concreto y en lo abstracto como "un foro para la búsqueda de la verdad". ${ }^{12}$ Una búsqueda basada en el pluralismo y en las libertades fundamentales que se entienden como derechos culturales básicos. Derechos a la libertad cultural en los tres ámbitos principales en que se pretende que la verdad opere: ciencia, arte y religión.

7 Häberle, Peter, op. cit., nota 4, pp. 133 y 134. Al respecto, conviene consultar: el apartado intitulado "Fundamentos teóricos de la Constitución democrática a la luz del pensamiento posibilista" en la obra Häberle, Peter, Pluralismo y Constitución, trad. de Emilio Mikunda-Franco, España, Tecnos, 2002. Desarrollo teórico que tiene sustento en las estructuras teóricas de Karl Raymund Popper, tales como "racionalismo crítico" y "sociedad abierta".

8 Häberle, Peter, op. cit., nota 2, p. 60.

9 Häberle, Peter, op. cit., nota 1, p. 113.

10 Idem.

11 Häberle, Peter, op. cit., nota 4, p. 48.

12 Häberle, Peter, op. cit., nota 1, p. 119. Es importante hacer notar que lo que el autor propone es el respeto a la autodeterminación y manifestación cultural, en lo individual y en lo colectivo, como medios para la comprensión y el entendimiento de los hombres; sin que ello implique que las razones para la acción cívica o privada puedan justificarse con la arbitrariedad o dogma alguno que atenten contra la dignidad humana. En los ámbitos cívico y académico, Häberle expresa que es necesario cumplir con las formalidades del pensamiento racional propio de los ambientes democrático y científico respectivos. 
En este tema Häberle es un filósofo contemporáneo que abandona todo fanatismo epistémico, propone un modelo científico, y construye un modelo político "sobre la remplazabilidad y perceptibilidad de cualquier 'verdad', entendiendo esto fundamentalmente en plural y no en singular, sin imponer nada" ${ }^{3}$. Según el propio Häberle, la propuesta de K. R. Popper sobre "la sociedad abierta" 14 "presenta la mejor manera, en palabras y procesos, de la relación del Estado constitucional con el problema de la verdad"15, al tiempo que, de acuerdo con Popper, la fundamentación primordial de la ciencia de la sociedad pluralista es el "racionalismo crítico".

Häberle añade que también debe ser admitida una variedad de propuestas teóricas y metodológicas provenientes de las posturas clásicas, antiguas y contemporáneas. Entre los autores contemporáneos a considerar cita a $\mathrm{H}$. G. Gadamer, J. Derrida o J. Habermas y, muy especialmente, a los grandes poetas entre los que cita a Goethe, Schiller y Lessing. ${ }^{16}$

Descendiendo en el nivel de abstracción, Häberle sugiere que para cada materia sea escuchada la opinión de los especialistas de cada ámbito e incluso de los involucrados en cada temática, expertos o no, buscando la "verdad por consenso". Así, el concepto de verdad crítica impera no solo para el ámbito cultural individual, incluyendo la perspectiva científica, sino que se traslada a un modelo de sociedad "ajeno a cualquier concepción confesional del mundo", ${ }^{17}$ "las democracias plurales representan la forma del Estado en donde la verdad es relativa". ${ }^{18}$

Partiendo del concepto de verdad como búsqueda inagotable, concluido a partir de la multiplicidad de verdades o regímenes de verdad y de la condición de inalcanzable de la verdad y la falibilidad humana ${ }^{19}$, los modelos teórico y político propuestos por Häberle pretenden generar el ambiente

13 Ibidem, p. 114.

14 Häberle, Peter, op. cit., nota 4, p.48.

15 Häberle, Peter, op. cit., nota 1, p. 114.

16 A pesar de que en la obra de Häberle no se encuentra una explicación precisa sobre cómo debe presentarse dicha admisión de teorías, se puede consultar un trabajo en el que este principio se lleva a la acción: Häberle, Peter, op. cit., nota 1. Se sugiere revisar el texto íntegramente analizando la forma en que se presentan las distintas acepciones del término "verdad". La explicitación de este mecanismo es una tarea pendiente para el propio Häberle o para quienes estudian su obra.

17 Häberle, Peter, op. cit., nota 1, p. 120.

18 Ibidem, p. 17.

19 Ibidem, p. 142 (síntesis). 
propicio para el ejercicio de la libertad cultural, comenzando en las vertientes básicas de religión, ciencia y arte. La verdad no pierde su valor científico ni socio-político, por el contrario, se vuelve un elemento fundamental del Estado constitucional y de la disciplina que lo observa y conforma, y se reconceptualiza, alejada del fundamentalismo epistémico. Las instituciones científicas y jurídico-políticas deben tener como premisa y objeto la protección de estas libertades en tanto que constituyen culturalmente a cada miembro de la humanidad; garantizarlo es el principal objetivo del Estado constitucional. Esto significa entender la Constitución como cultura y a la disciplina que la estudia como ciencia de la cultura. ${ }^{20}$

A partir de las variaciones en el concepto de verdad, según la especialidad científica e incluso al interior de una misma disciplina, ${ }^{21}$ Häberle propone que se hable del "concepto multifuncional y relacional de la verdad." ${ }^{22}$ Eso demanda la combinación de diversas teorías que él llama "de la correspondencia", "de la coherencia" y "del consenso", con el fin de incorporar la teoría de la "verdad por consenso"23 como "permanente elaboración de "consensos básicos" y siguiendo el sentido se los consensos éticos mínimos". ${ }^{24}$

Si se entiende lo que Häberle propone, es necesario entonces partir de la teoría clásica de la verdad como predicado semántico ${ }^{25}$, que postula que una aseveración es verídica si lo expresado corresponde con el caso señalado; teoría recurrentemente mencionada como "de la correspondencia". ${ }^{26}$ Las teorías a conjuntar a un lado de esta primera serían las siguientes: a. la teoría "de la coherencia" que propone que la verdad sea entendida como "la inclusión coherente de una oración dentro del complejo de enunciados científicos", ${ }^{27}$ es decir, que "una aseveración es verdadera "si y solo si forma parte de un sistema de aseveraciones interdependientes y libres de contradicción", ${ }^{28}$ y b. la teoría "del consenso", propuesta por diversos autores, pero muy principalmente por J. Habermas, que "entiende verdad

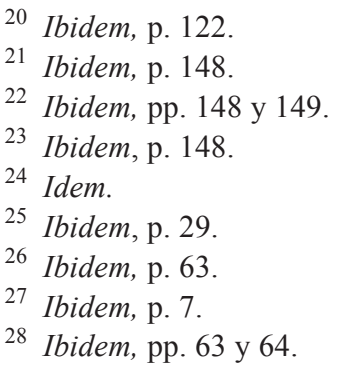


como la conformidad de una afirmación de los participantes de la comunidad, siempre y cuando obviamente esta comunicación se encuentre guiada por la comunicación libre y universal". ${ }^{29}$

Evidentemente la propuesta häberleana no es la mezcla o confusión de estas teorías ni el sincretismo teórico a este respecto. Lo que propone Häberle es una "mesa redonda" de las verdades, de invitación siempre abierta, en la que todas las propuestas honestas y razonables sean escuchadas, y el debate produzca una verdad colectiva aceptada, propia de un tiempo y un espacio determinados; "una concepción democrática de la verdad". ${ }^{30}$

29 Ibidem, p. 8.

30 Ibidem, p. 128. En este tema puede sostenerse que Häberle suscribe íntegramente los postulados del "racionalismo crítico" de K. R. Popper, el cual es descrito en su obra: "La sociedad abierta y sus enemigos". Este es el rasgo cultural fundamental de la sociedad abierta, mismo que puede sintetizarse de la siguiente manera:

El basamento se encuentra en la confianza, en la razón como mecanismo útil para el mejoramiento de los asuntos humanos. El pensamiento es dotado de espíritu crítico, entendido como el motor de la búsqueda constante y eterna de la verdad; empresa en la que la regla fundamental es que ninguna verdad puede tomarse como definitiva. La aceptación de la crítica como instrumento racional implica la adopción de la autocrítica.

La creatividad humana es valorada como la fuente de todas las ideas, lo que hace que los ataques a la libertad intelectual no sean admisibles. Las ideas, como producto de la creatividad intelectual, deben ser sometidas a criterios racionales estrictos para ser tomadas en cuenta en el juego de la generación y acumulación de aquello que se considera conocimiento. Entre estos criterios se cuenta principalmente con la intersubjetividad y el contraste poli-instrumental; dejando de lado tanto la subjetividad como la objetividad ingenua.

El debate formal, en el que cada individuo participa adoptando y respetando las reglas racionales, es el mecanismo práctico correlativo a este rasgo cultural. En ese debate toda idea que pretenda ser impuesta o inmutable es descalificada de inicio para participar. La adopción, sostenimiento o cambio de ideas son producto del juego de la racionalidad. Se busca un mundo racional en el que la guerra reglamentada de las ideas sustituye a la guerra entre los hombres.

Se pretende que la cultura social sea cada vez más producto de la razón individual, en sustitución de toda verdad tradicional. La confianza en la razón permite al hombre afrontar la incertidumbre, lo desconocido y lo inestable, incluyendo todo aquello que se encuentra más allá de su actual conocimiento, entre lo que se incluye su propio futuro.

3El racionalismo crítico es un rasgo cultural que se opone al dogmatismo, propio de la sociedad cerrada, en el que se desprecia la racionalidad humana poniendo acento en la irracionalidad. En este ambiente las razones para la acción provienen principalmente de las emociones, el pensamiento mágico y tabúes inmutables que se institucionalizan. La verdad se concibe como definitiva y universal. El argumento de autoridad impera, por lo que las ideas son impuestas y no se admite su debate a la luz de la racionalidad. El adoc- 
En materia científica, la propuesta es la multidisciplinariedad y la admisión de todo modelo teórico resumidos en una "gran antropología". En materia del modelo político, opina que cada Constitución nacional no debe "abrevar de sólo una gran teoría, si se pretende que ésta se mantenga como Constitución del pluralismo". ${ }^{31}$ Häberle considera que si el "tipo" Estado constitucional llega a imponerse hegemónicamente en el mundo, el concepto de verdad, como aquella que "es capaz de hacerse valer en cada uno de los contextos bajo aspectos técnicos específicos, o como gran objetivo general", llegará a hacerse un paradigma hegemónico. ${ }^{32}$

La naturaleza compleja del objeto de estudio es lo que justifica la multidisciplinariedad propuesta por Häberle. Complejidad que ahora nos disponemos a exponer.

\section{EL PRODUCTO Y LA METODOLOGÍA}

\section{El "tipo" Estado constitucional}

Como concepto académico, el "tipo" Estado constitucional es producto del estudio comparado de los contenidos y procedimientos esenciales de las Constituciones democráticas del mundo entero, teniendo como fundamento teórico fáctico la "teoría de la Constitución como ciencia de la cultura" y utilizando el planteamiento teórico-metodológico propuesto por Häberle.

El arquetipo resultante pretende tener fuerza explicativa. Busca, igualmente, servir como guía para la acción. Es también una teoría constitucional normativa, como es propio de un constitucionalista. El tipo Estado constitucional es un paradigma, en el sentido clásico del término, es decir, una disciplina conformada con criterios que, de no encontrarse en el caso, éste no puede ser calificado como tal. Es también un paradigma entendido como matriz disciplinar, en el sentido propuesto por Thomas Khun, al menos así es para Peter Häberle y para quienes lo adopten para trabajar con él. Veamos el porqué.

trinamiento es un recurso formativo útil para perpetuar los rasgos culturales. La crítica es rechazada y suprimida en lo posible.

31 Häberle, Peter, op. cit., nota 4, pp. 115 y 126.

${ }^{32}$ Häberle, Peter, op . cit., nota 1, p. 36. 
Nuestro autor señala que el "tipo" está compuesto por elementos ideales y reales. Esos elementos no se encuentran en un único texto constitucional ni en ninguna Constitución, sino sólo en el arquetipo que se obtiene conjuntando los elementos comunes de varias Constituciones. Ese modelo es conformado por todo "lo típico" en relación con los diversos temas, principios y procedimientos del Estado constitucional. ${ }^{33}$ Este tipo debe ser desentrañado por medio de la comparación histórica y contemporánea de textos y contextos constitucionales. Es un proyecto universal, a pesar de la diversidad de las culturas nacionales. Este tipo puede describirse como la cultura constitucional universal, entendiendo el universo como la comunidad mundial de Estados constitucionales; como el derecho constitucional "común" a los Estados miembros de dicha comunidad; el ius commune universal.

El tipo Estado constitucional debe ser entendido como un conjunto de elementos extraídos de la cultura constitucional universal, seleccionados como su parte medular, a partir de un proceso constante de comparación. Como objeto de estudio es un producto comunitario proveniente de contribuciones parciales de muchas naciones, "formalizado en textos jurídicos y contextos culturales, de muchos tiempos y muchos lugares". ${ }^{34}$ Los elementos, conformados por contenidos, formas y procedimientos provenientes de múltiples naciones y teniendo origen histórico muy diverso se reúnen para conformar y articular el tipo. ${ }^{35}$

Este arquetipo es entendido por Häberle, en última instancia, como "un patrimonio común de bienes espirituales"36 (desde la función definitiva del "tipo"), y como un conjunto de "indicadores y expresiones tendenciales de un patrimonio común y de una tarea para el futuro" 37 como un respetuoso "mandato a la humanidad" (desde la función prescriptiva del "tipo").

33 Häberle, Peter, El Estado constitucional, trad. de Héctor Fix-Fierro, México, Instituto de Investigaciones Jurídicas, UNAM, 2003. p. 145 (síntesis).

34 Häberle, Peter, Libertad, igualdad, fraternidad, 1789 como historia, actualidad y futuro del Estado constitucional, trad. de Ignacio Gutiérrez Gutiérrez, Madrid, Trotta, 1998 , p. 68.

35 Ibidem, p. 80 (síntesis).

36 Häberle, Peter, op. cit., nota 5, p. 279.

37 Ibidem, p. 321. 


\section{Nivel abstracto y nivel concreto (unidad y diversidad)}

La generalidad del "tipo" se corresponde con la particularidad de cada configuración nacional respectiva. El Estado constitucional como "tipo" es la parte abstracta del mismo. Es el conjunto de rasgos comunes que desde la mayor abstracción genera una unidad cultural. La parte concreta es la Constitución específica e individual de un pueblo, la cultura constitucional particular que al observarse de cerca permite ver que la unidad se integra a partir de la diversidad. La teoría del "tipo" constitucional como "la buena Constitución del Estado constitucional" 38 intenta desarrollar métodos y contenidos que, no obstante la lucha por participar en la conformación del "tipo", dejen amplios espacios de libertad para disponer los elementos conforme a las condiciones de lo histórico-individual. "La riqueza de formas, procedimientos y contenidos es grande, porque el tipo Estado constitucional ofrece bastante margen de configuración". ${ }^{39}$ En la disciplina trazada por Häberle, la labor del científico consiste en hacer "política científica de reservas", es decir, generar material que sirva como base del montaje para las constituciones concretas, ${ }^{40}$ elaborar un espectro de varias alternativas que puedan ser de utilidad para quien haga política constitucional, llenar el "cajón de instrumentos" instrumental no puede calificarse como constitutione ferenda, puesto que no pretende sugerir particularidades para una Constitución en concreto, la cual debe, en todo caso, tomar los elementos del tipo que le sean útiles y ajustarlos a sus necesidades, todo ello dentro de cada contexto cultural específico. Así entendida, la política constitucional no debe ser excluida de la labor de los juristas, como científicos, por estar demasiado "próxima a la política". Debe concebirse como parte integrante de la disciplina en la que trabajan unidas la política constitucional y la teoría jurídica.

38 Häberle, Peter, op. cit., nota 33, p. 139.

39 Ibidem, p. 253.

40 Häberle, Peter, Constitución como cultura. Artículos seleccionados para Colombia, trad. de Ana María Montoya, Colombia, Instituto de Estudios Constitucionales Carlos Restrepo Piedrahíta, Universidad del Externado de Colombia, 2002, p.103 (síntesis).

41 Häberle, Peter y Kotzur, Markus, op. cit., nota 3, p. 71. 


\section{La sociedad abierta de los intérpretes constitucionales ${ }^{42}$}

Para comprender este apartado es necesario tener en cuenta que, al igual que en todos los elementos de la teoría haberleana, la exégesis constitucional propuesta "significa, en parte, programa y, en parte, también realidad y actualidad". "Häberle advierte que la teoría de la interpretación constitucional se ha planteado tradicionalmente las cuestiones de las funciones, los objetivos y los métodos de la misma, dejando de lado el estudio de los participantes en el proceso de interpretación constitucional.

En este tema, la premisa básica proviene de la idea fundamental de Karl Popper de "la sociedad abierta" ${ }^{44}$ como rechazo de todos los sistemas totalitarios.

Partiendo de una postura realista antropológica y teniendo como fundamento la premisa de la "sociedad abierta", en la que todo lo que atañe a la res pública debe ser igualmente público, nuestro autor sostiene que "los procesos de interpretación son dependientes, material y personalmente, de lo cultural y no primariamente de lo jurídico" ${ }^{45}$ La teoría de la interpretación constitucional tradicionalmente se ha concentrado demasiado en la "sociedad cerrada" de intérpretes constitucionales, constituida nuclearmente por el juez constitucional, perdiendo de vista que la Constitución es no únicamente un texto sino un contexto cultural que permite darle sentido. Por lo que Häberle sugiere un nuevo planteamiento en el que no exista ningún "numerus clausus" y que considere dentro de la sociedad de intérpretes constitucionales a todos los órganos del Estado, todos los poderes públicos, todos los grupos, todas las instituciones y todos los ciudadanos y se analice el ambiente cultural.

Desde esta perspectiva, todos estos intérpretes actúan al menos como "intérpretes previos, mediatos o a largo plazo". "El espacio público pluralista despliega fuerza normativa y el tribunal constitucional debe interpretar más tarde en correspondencia con ese espacio cultural". La responsabilidad recae en la jurisdicción constitucional "en tanto intérprete último". Incluso la interpretación constitucional parte, y debe hacerlo, del criterio de los

42 Häberle, Peter, op. cit., nota 33 p. 149, y Häberle, Peter y Kotzur, Markus, op. cit., nota 3 p. 109 (síntesis).

43 Häberle, Peter, op. cit., nota 2, p. 102.

44 Häberle, Peter, op. cit., nota 4, p. 48.

45 Häberle, op. cit., nota 33, p. 36. 
propios ciudadanos destinatarios de la norma, sus opiniones pueden ejercer influencia". El sentido común participa en la exégesis abierta.

La jurisdicción constitucional no tiene la tarea de formar teorías, ella tiene la tarea pragmática y referida al caso particular de conciliar teorías. Sostener exclusivamente una teoría es incongruente con la sociedad pluralista y abierta que constituye el sustento y el contexto de esta perspectiva; lo cual no se contrapone con la conformación de un "núcleo teórico universal consensuado sobre el fondo del postulado de la apertura y la revisabilidad". ${ }^{46}$

Häberle hace ver que en la interpretación constitucional todos los participantes son "corresponsables", ${ }^{47}$ aunque cada actor participa de manera diversa y "con intensidad variable" específica. Las concepciones de los elementos constitucionales de todos los intérpretes constitucionales en sentido amplio, son aquello que da a la interpretación constitucional legitimidad básica, teórica y democrática. ${ }^{49}$ Lo anterior sin perder de vista que existen ciertos "actores particularmente calificados" ${ }^{\prime 50}$ como lo son los órganos del Estado y la comunidad científica respectiva. Con lo cual, sugiere Häberle, debe darse una especie de valoración paralela entre el sentido jurídico de los ciudadanos y el de los intérpretes particularmente calificados. El maestro alemán también observa que la interpretación constitucional puede ser ajena a la participación del juez constitucional, ya sea por falta de competencia o por ausencia de promoción de instancias ante el tribunal, o ajena incluso a la participación de todo órgano del Estado, y a pesar de ello la Constitución "vive". Aquí se evidencia que la "comprensión" de las normas y "auto-comprensión" de los destinatarios de las propias normas es también esencialmente jurídica. Ésta es la visión de "la Constitución como proceso abierto" en la que todos los miembros del "inventario" de intérpretes hacen "filigrana" constitucional, no sólo el jurista constitucional. Concepción que tiene como fundamento "el pluralismo y la apertura de input" ${ }^{51}$ de todo proceso de interpretación constitucional. Perspectiva desde la que el Estado es entendido no más

\footnotetext{
46 Häberle, Peter, op. cit., nota 5, p. 263 (resumen).

47 Ibidem, p. 336.

48 Ibidem, p. 335.

49 Häberle, Peter, op. cit., nota 2, p. 90 (síntesis).

50 Häberle, Peter, op. cit., nota 5, p. 334.

51 Häberle, Peter, op. cit., nota 2, p. 109.
} 
como "algo dado que está ahí, sino como un objeto de debe ser configurado a cargo de todos". 52

Igualmente, Haberle sostiene que la teoría de la interpretación constitucional tradicional ha sobreestimado la importancia del texto constitucional y descuidado el contexto cultural, sobre todo si se toma en cuenta que el contenido de los textos constitucionales (como el de todos los textos) es el contexto cultural en última instancia. Es por ello que afirma que los textos clásicos ayudan en su labor al intérprete constitucional, intérprete en sentido amplio, desde el ciudadano hasta el juez constitucional.

Para comprender esto es necesario atender a las afirmaciones de Häberle en el sentido de que la controversia particular que hace necesaria la interpretación constitucional por parte del juez constitucional puede ser clausurada por la resolución del órgano jurisdiccional, pero nunca se ve clausurada la interpretación general del texto que permanece necesariamente abierta. En este ámbito, quienes tienen la siempre "penúltima palabra" son la opinión pública científica y general". ${ }^{53}$ Nuestro autor nos hacer ver que "las reglas no estructuran de manera rígida e inmutable una situación, sino que la estructura de la situación es producida por la común negociación e interpretación de aquellos que participan de la situación". ${ }^{54}$

Derivado de estos argumentos, Häberle considera que conservar el inventario de la sociedad cerrada de intérpretes constitucionales es un empobrecimiento teórico o un autoengaño. Lo cual no debe interpretarse como una manifestación en contra de la dogmática, sino a favor de una dogmática abierta o flexible, basada en la revisabilidad constante de su contenido, por medio de un proceso amplio de interpretación legitimada en la comunidad de ciudadanos plural.

\section{La comparación en el tiempo y en el espacio}

Como "tipo", el Estado constitucional es una "suma parcial de filosofías políticas, textos de los clásicos, programas de partidos, saber derivado de la experiencia, incluso de las "heridas" de numerosas generaciones,

52 Ibidem, p. 174.

53 Häberle, Peter, El Tribunal Constitucional como Tribunal Ciudadano. El recurso constitucional de Amparo, trad. de Joaquín Brage Camazano, México, Fundap, 2005, p. 156.

54 Häberle, Peter, op. cit., nota 5, p. 263. 
así como de utopías concretas; es también una suma parcial de procesos revolucionarios y evolutivos". ${ }^{55}$ Las grandes fechas de la historia constitucional lo evidencian. La constatación de similitudes y diferencias entre el ahora y el entonces permite reconstruir un proceso evolutivo de los textos y los contextos constitucionales.

La observación de los procesos de producción y recepción de una nación a otra en materia de Estado constitucional, es permitida por la comparación contemporánea de los textos y los contextos, éste es un trabajo en la dimensión complementaria. Los textos constitucionales más recientes adoptan lo desarrollado a partir de los textos más antiguos.

\section{Los clásicos}

En el ambiente cultural en el que los textos constitucionales son interpretados, destacan los textos clásicos en materia de derecho político, ya que abarcan la parte esencial del perfil del Estado constitucional. ${ }^{56}$ Comencemos por entender lo que Häberle considera un texto clásico. Los textos clásicos son aquellas obras que cumplen con dos requisitos. Por una parte, en el aspecto valorativo, son las obras de más alta calidad en cuanto a sus aportaciones, en la que el grado máximo es la inauguración paradigmática. Por la otra parte, en cuanto a lo cuantitativo se incluyen las obras con más amplio consenso en el espacio y en el tiempo. Podemos decir que se refiere a las obras cumbre de la cultura constitucional mundial, entre las que se encuentran textos constitucionales, jurisprudenciales y doctrinarios, ya sean jurídicos o de cualquier área cultural; se incluyen también instrumentos no textuales, especialmente las grandes obras artísticas. ${ }^{57}$

Para Häberle, los elementos del tipo Estado constitucional, siendo productos culturales, comparten las mismas fuentes que la cultura en general. Desde luego, se caracterizan porque trascienden en el tiempo y el espacio constitucionales de manera que se incorporan al modelo. El contenido cultural de documentos como el Virginia Bill of Rights, los Federalist Papers o la Declaración francesa de los Derechos del Hombre y del Ciudadano, o de obras pertinentes de autores como Aristóteles, Cicerón, Locke, Hobbes, Montesquieu, Rousseau, Sieyes, Kant, Marx, Popper, Jonas,

${ }^{55}$ Häberle, Peter, op. cit., nota 33, p. 45.

${ }^{56}$ Häberle, Peter, op. cit., nota 34, p. 35.

${ }^{57}$ Häberle, Peter, op. cit., nota 4, p.198. 
Rawls, Habermas y Alexy, influyen fácticamente en el proceso de formación de las Constituciones del Estado constitucional primero, y desarrollan el tipo de Estado constitucional después. Es claro que estos textos tienen "una validez de tipo normativo, legítima, aunque limitada. ${ }^{58}$ Los textos clásicos actúan como contexto escrito en relación con un texto constitucional, son textos constitucionales en sentido amplio. ${ }^{59} \mathrm{El}$ trabajo preparatorio para la interpretación constitucional es realizado por la doctrina, especialmente por los textos clásicos, en ellos se encuentra la legitimidad contextual, como se observa en la argumentación de toda resolución constitucional bien sustentada, en la que necesariamente se recurre a ellos como método de justificación.

Debe destacarse que la propuesta de Häberle incluye todas las facetas de la cultura, por lo que entre los clásicos refiere, incluso, principalmente a los artistas en todas las expresiones posibles. Menciones constantes en su obra son Schiller, Goethe, Brecht, Mushg, Shakespeare, Cervantes, Víctor Hugo, García Lorca, Kafka, Orwell, Beethoven, Mozart, Bach, Wagner, Rembrandt, Picasso, Delacroix, hasta The Beetles, entre muchos otros cuyas obras pueden pertenecer desde la alta cultura hasta la cultura trivial. Para Häberle, los poetas ejercen principalmente la crítica, ${ }^{60}$ al mismo tiempo que "proporcionan la suficiente dosis de utopía que orienta el sentido de la realidad constitucional". ${ }^{61}$ Cuando nuestro autor, a lo largo de su obra, expone el origen de los elementos de su teoría y del tipo Estado constitucional, deja ver que muchos de los "gérmenes" del Estado constitucional y de la teoría que lo concibe, tienen origen en la labor del gremio artístico, principalmente de los poetas. ${ }^{62}$ Por ello, a cambio de su gran aporte, el Estado constitucional tiene como obligación convivir con las ególatras diferencias que el artista representa. ${ }^{63}$ Corresponde al Estado constitucional, equilibradamente, garantizar la autonomía de la cultura, renunciando al dirigismo y, por supuesto, al monopolio del Estado en materia de "contenido" cultural, sin retirar el apoyo para su preservación y desarrollo.

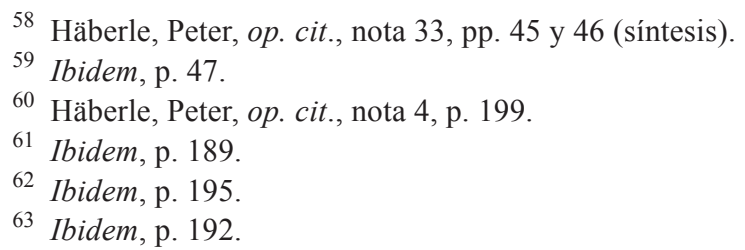




\section{El paradigma de los niveles textuales}

Häberle afirma que la evolución constitucional, propiciada por el proceso constante de exportación-importación internacional de elementos de cultura constitucional, se puede analizar comenzando por la observación del intercambio de textos constitucionales. El tipo Estado constitucional es un proyecto siempre abierto que se desarrolla en el nivel de maduración de los textos. Su evolución comienza en Europa con la ideas de Locke, Montesquieu, Rousseau, Adam Smith; pasando por la Declaración de Derechos de Virginia y la Declaración de Independencia de los Estados Unidos; lo cual remonta al derecho romano y finalmente a la cultura griega antigua. ${ }^{64}$ Todas las culturas nacionales de occidente han realizado algunas aportaciones importantes, hoy en día incluso las naciones que recientemente se incorporan a la comunidad de Estados constitucionales lo hacen.

Lo que en un Estado todavía no se expresa como texto, "se desarrolla en otro como realidad constitucional a través de la práctica de las autoridades públicas. Más tarde el estado vecino recibe, a través de la elaboración de un nuevo texto constitucional o de una reforma, esa realidad hasta entonces ajena, la transforma en textos y conceptos, dando continuidad a la antigua Constitución y llevándola a una nueva etapa". ${ }^{65}$ Los constituyentes conocen la historia constitucional propia y ajena, y la comparan para luego convertirla en texto. "Por ello, los textos constitucionales recepcionados son escritos de forma más inteligente que los originales" ${ }^{66}$ Así, el proceso comienza con la producción o renovación de los elementos del arquetipo en cualquiera de las sociedades abiertas del sistema o comunidad mundial de Estados constitucionales. Luego, la contribución particular entra en el "torrente teórico" que circula en todas direcciones y termina con la recepción creativa en los diferentes miembros, en donde se inicia nuevamente el ciclo.

\section{La comparación jurídica-cultural como quinto método de interpretación constitucional}

La "teoría de la Constitución como ciencia cultural" puede ser caracterizada como una teoría constitucional comparada desde una perspectiva cosmopolita.

64 Ibidem, p. 89, 94.

65 Häberle, Peter y Kotzur, Markus, op. cit., nota 3, p. 13.

66 Ibidem, p. 7. 
Su objeto de estudio es la cultura constitucional universal a partir de las particularidades y comenzando por los textos constitucionales en sentido amplio. Aquí "comparar constituciones equivale a una comparación de culturas", ${ }^{67}$ en su aspecto constitucional desde luego. Esta labor comparativa debe realizarse por todos los participantes en los procesos de interpretación constitucional, ${ }^{68}$ aunque de manera primordial corresponde a los científicos en los ámbitos de la política y la interpretación constitucionales.

En el proceso de interpretación ius-comparada que persigue la identificación del derecho constitucional común, el intérprete trabaja a nivel textual, teórico y práctico. Debe tomar en cuenta la totalidad de las normas constitucionales vigentes en cada uno de los Estados estudiados, incluyendo toda fuente de la cultura constitucional respectiva, aun cuando proceda al estudio de un sólo elemento constitucional. El proceso inicia comparando los textos jurídicos, continuando con la praxis jurídica elaborada científicamente, para finalmente referirse a los elementos pertinentes del contexto cultural. Una junto a otra, las culturas constitucionales relativas a cada elemento constitucional son cotejadas identificando sus paralelismos y coincidencias y eliminando las particularidades. Esta es la parte cualitativa de la labor. La parte cuantitativa consiste en determinar si el número de culturas constitucionales que comparten un determinado concepto jurídico es suficiente para considerarlo como "derecho común" y, por tanto, como parte del "tipo" Estado constitucional. ${ }^{69}$ De forma paralela a este estudio, es necesario el estudio de la historia de las instituciones constitucionales. Observar y razonar el proceso de exportación-importación de elementos entre los distintos Estados constitucionales. La finalidad es comprender el desarrollo gradual y cooperativo de cada uno de esos elementos para detectar las tendencias históricas y las razones de las mismas.

El derecho comparado es así no sólo un elemento real oculto, sino que se desvela para aprovechar todo su potencial y se le utiliza en el ámbito de la teoría jurídica y de la política constitucional. La comparación jurídica se convierte en la tarea normal del jurista y en un "modo especial de legitimación" de la actividad jurisdiccional a nivel constitucional.

Esta perspectiva teórico-metodológica propuesta por Häberle amplía y profundiza la labor tradicional del jurista pero no pretende eliminarla, de

67 Häberle, Peter, op. cit., nota 4, p. 127.

68 Häberle, Peter, op. cit., nota 65, p. 18.

${ }^{69}$ Ibidem, pp. 19-21 (síntesis.). 
manera que subsiste el papel disciplinador de la dogmática y los cuatro métodos interpretativos tradicionales a los que se suma el comparativo. Recordemos que este enfoque pretende la sensibilización del derecho constitucional hacia los factores que actúan antes y después de las normas jurídicas. $^{70}$

El método comparativo propuesto por Häberle plantea el análisis en dos dimensiones: tiempo y espacio. El resultado es una imagen mixta generada a partir de una visión diacrónica o histórica junto a una visión sincrónica o espacial contemporánea. Esa imagen proviene de un objeto de estudio compuesto por una triada: textos, teorías y sentencias constitucionales. Éstos conforman una síntesis variable, unas veces es suficiente el simple texto constitucional, otras veces éste requiere de la interpretación jurisprudencial constitucional para adquirir significado y sentido plenos y en ocasiones es interpretable con la ayuda de las teorías. ${ }^{71}$ Finalmente, el contexto jurídicocultural determina el contenido de los textos jurídicos. Así, los textos constitucionales conforman únicamente " $u n$ acceso a la realidad entera del Estado constitucional". ${ }^{72}$

En este marco, la comparación jurídico-cultural se vuelve indispensable como método de interpretación. Si bien el método comparativo en el tiempo y en el espacio tiene como objeto los textos (en sentido amplio), las teorías y las sentencias ${ }^{73}$ en general, con vistas a la conformación del arquetipo, su objeto primordial y final son los textos clásicos, desde Aristóteles hasta Popper y Rawls. Dentro de los textos jurídicos, deben incluirse lo local, nacional, regional e internacional; de lo cual no se excluye la posibilidad de acotar el estudio a un ámbito parcial o ampliarlo al universal, siendo toda posibilidad productiva. La comparación constitucional, entendiendo a la Constitución como cultura jurídicopolítica, es la vía para que las distintas constituciones se comuniquen. De esta forma la fuerza conformadora del tipo Estado constitucional adquiere un alto grado de eficacia.

Häberle hace ver que la comparación jurídica opera en dos planos, la realizada por los tribunales al momento de la interpretación y la hecha por parte de la política jurídica. "Esta comparación es llevada a cabo

70 Häberle, Peter y Kotzur, Markus, op. cit., nota 3, p. 9 (síntesis).

71 Ibidem, p. 12 (síntesis).

72 Ibidem, p. 57.

73 Ibidem, p. 11. 
constantemente de manera no explícita; debería hacerse de manera abierta"74 y profunda. "Debería ser practicada de modo aún más consciente y mucho más refinado" 75 y tomando en cuenta "los principios, los textos y los paradigmas que anteceden filosóficamente a las normas jurídicas" ${ }^{76}$ Para nuestro autor, el método comparativo debe ocupar, cuando menos el quinto lugar, sino es que el preeminente. ${ }^{77}$

\section{Los " $n$ " mandamientos (el inventario actual de elementos del "tipo")}

Según Häberle, el catálogo "siempre abierto" de principios, el conjunto de los datos ideales del "tipo", el listado de los elementos típicos del Estado constitucional contemporáneo es el siguiente: la dignidad humana como premisa, la garantía de los derechos humanos fundamentales, el principio de igualdad, la democracia efectiva, el principio del pluralismo, el principio de la tolerancia, el principio de la soberanía popular, el principio de laicidad o neutralidad del Estado, la Constitución como contrato, el principio de la división de poderes, el federalismo o regionalismo, los principios del Estado de derecho, del Estado social y del Estado cultural, la independencia de la jurisdicción, la pluralidad de partidos, la protección de minorías, el principio de desarrollo sustentable ecológicamente, la jurisdicción constitucional, la supremacía constitucional, la vigilancia ciudadana de los derechos humanos, la economía social de mercado, la protección del medio ambiente, la protección de las culturas autóctonas, órganos defensores del pueblo, la Constitución escrita... ${ }^{78}$

El anterior es un listado de límites típicos que conforman el programa constitucional obligatorio, "que si no se respetan, conducen a que no se pueda hablar de Estado constitucional". ${ }^{79}$ De esta manera puede afirmarse que, desde el punto de vista jurídico-político, todo pueblo tiene una Constitución; mientras que, considerado culturalmente de modo más amplio y si se utiliza

74 Ibidem, pp. 14 y 15.

75 Häberle, Peter, op. cit., nota 5, p. 336.

76 Häberle, Peter y Kotzur, Markus, op. cit., nota 3, p. 15.

77 Häberle, Peter, op. cit., nota 33, p. 162 (síntesis).

78 El listado proviene de todas las obras de Häberle consultadas para la elaboración de este trabajo. Se puede encontrar una buena parte de los elementos referidos, de manera conjunta, en: Häberle, Peter, El Estado constitucional, trad. de Héctor Fix-Fierro, México, UNAM, Instituto de Investigaciones Jurídicas, 2003, pp. 1 y 2.

${ }^{79}$ Häberle, Peter, op. cit., nota 33, p. 288. 
el tipo para calificar las condiciones de un Estado, éste se encuentra "en mejor o peor forma constitucional". 80

\section{EL PROYECTO ESTADO CONSTITUCIONAL}

En la obra de Peter Häberle el "Estado constitucional" es una cosmovisión. Puede decirse que no es, únicamente, su objeto de estudio, sino que es su proyecto de vida académica; es realidad observable y proyecto teórico en constante desarrollo. La obra de este jurista puede estudiarse como una estructura estratificada. En la parte básica, sus productos plantean los fundamentos de su labor en general; las premisas teóricas son expresadas con mucha concisión, mientras que el objeto de estudio es dibujado a finos y ligeros trazos hasta que alcanza un alto grado de identificación. La ubicación del objeto de estudio en el tiempo y en el espacio es el tema del siguiente estrato de su discurso. En el tercer nivel, entra ya en la construcción teórica, exponiendo los presupuestos del Estado constitucional en tanto realidad e idealidad. Finalmente, se ocupa del aspecto dogmático, reflexiona sobre la problemática humana que el derecho puede y debe ayudar a resolver. Cabe mencionar que el planteamiento anterior no es cronológico, todos estos temas aparecen en mayor o menor grado en cada una de sus obras, en las cuales nunca deja de ajustar o aclarar sus pensamientos previos en todos los niveles discursivos. ${ }^{81}$

Para esclarecer lo que se entiende como "Estado constitucional" por parte de Peter Häberle, es necesario hacer una revisión reiterada de buena parte de la obra de este autor; pues, como él mismo lo declara, el producto de su trabajo académico no resulta fácil de asir. A continuación se intentará plasmar los rasgos generales básicos de este concepto. Esto nos coloca "como enanos sobre hombros de gigantes", ${ }^{82}$ como el mismo Häberle sugiere, al tiempo que constituye una respuesta positiva a la invitación hecha por este "gigante" contemporáneo a sumarse al análisis de la problemática constitucional desde

${ }^{80}$ Häberle, Peter, op. cit., nota 34, p. 47.

81 En cuanto a la estructura teórica de la obra de Häberle, se puede consultar la presentación hecha por Ignacio Gutiérrez Gutiérrez a la obra: Häberle, Peter, Libertad, igualdad, fraternidad, 1789 como historia, actualidad y futuro del Estado constitucional, trad. de Ignacio Gutiérrez Gutiérrez, Madrid, Trotta, 1998. p. 27.

82 Carbonell, Miguel y Valadés, Diego (eds.), La Constitucionalización de Europa, México, UNAM, Instituto de Investigaciones Jurídicas, 2004, p. 24 (resumen). 
la "teoría de Constitución como ciencia de la cultura", construida por él a lo largo de 50 años de investigación.

\section{La Constitución como cultura (la Constitución viviente)}

Un "asunto clave" para entender el concepto de Estado constitucional en el pensamiento de Häberle es "la Constitución como cultura". Para nuestro autor la Constitución no es únicamente un texto sino un contexto cultural, el ambiente que permite que el texto adquiera sentido. Si, como señala, el derecho constitucional en vigor en determinado tiempo y espacio no halla expresión plena en el texto de la Constitución correspondiente, entonces puede entenderse porqué para él es necesario entender que la Constitución es primordialmente cultura, un aspecto específico de ella.

En el pensamiento de Häberle, la cultura es entendida como "aquello creado por el ser humano", ${ }^{83}$ los seres humanos son sus portadores ${ }^{84}$ no se le encuentra en otro lugar. Para este teórico, la cultura es el mundo psíquico o espiritual de los miembros de una comunidad humana, no como suma cuantitativa sino como cosmovisión compartida, no como una masa fundida sino como una comunidad de entidades culturales individuales. Así, un Estado es una "unidad cultural" ${ }^{85}$ Häberle propone una clasificación de los elementos de la cultura en varias dimensiones: la cultura elevada o la alta cultura clásica, entendida como "lo verdadero, lo bueno y lo bello", no sólo antigua, sino de todos los tiempos; la cultura popular o folclórica como cultura de los aborígenes; la cultura de masas; la subcultura, y la cultura trivial o popular contemporánea. Correspondiendo a cada uno de estos ámbitos un conjunto de vertientes que conforman la cultura alternativa, y finalmente, la contracultura. Todas conviviendo, intercambiando y compitiendo en lo que concibe como el "concepto abierto de cultura". ${ }^{86}$ En esa perspectiva los objetos serán cultura en tanto los seres humanos les asignen un valor significativo: como ejemplos Häberle refiere objetos animados tales como

${ }^{83}$ Häberle, Peter, Constitución como cultura. Artículos seleccionados para Colombia, trad. de Ana María Montoya, Colombia, Instituto de Estudios Constitucionales Carlos Restrepo Piedrahíta, Universidad del Externado de Colombia, 2002, p. 63. También en Häberle, Peter, op. cit., nota 3, pp. 9 y 10.

${ }^{84}$ Häberle, Peter, op. cit., nota 5, p. 314.

${ }^{85}$ Häberle, Peter, op. cit., nota 4, p. 98.

${ }^{86}$ Häberle, Peter, op. cit., nota 33, p. 241. 
ciertos árboles, instrumentos musicales, máscaras, pinturas o esculturas de distintas culturas alrededor del planeta.

En la visión häberleana, para que una comunidad humana se considere una sociedad debe compartir al menos algunos rasgos culturales fundamentales, siendo admisible al mismo tiempo una gran diversidad en cuanto a las particularidades. Unidad de la diversidad, a partir de los elementos compartidos, sería un concepto "clave" y relativo al nivel de abstracción desde el que se observe la cultura constitucional.

Dentro de los rasgos culturales de una sociedad puede encontrarse, y esto constituye un requisito para ser calificada como Estado constitucional, un orden dirigido no sólo a juristas, sino que opere "en esencia, como hilo conductor para quienes no son juristas: para el ciudadano", ${ }^{87}$ como una "guía cultural", ${ }^{88}$ como un orden que configura y organiza a los órganos del Estado pero también, y primordialmente, a la comunidad. El concierto social es así el fin último de la Constitución.

En efecto, la Constitución es entendida, sí como un orden jurídico fundamental del Estado y de la sociedad, pero no sólo eso, también "como expresión de un estadio cultural", ${ }^{89}$ como "expresión de un nivel de desarrollo cultural, instrumento de la representación cultural autónoma de un pueblo, reflejo de su herencia cultural y fundamento de nuevas esperanzas". ${ }^{90}$ Häberle propone que el texto constitucional sea visto solo como una referencia a la cultura constitucional que es entendida como "expresión de un Estado cultural que sirve de medio para la autoconciencia de un pueblo, que funge como espejo de su legado cultural y fundamento de sus futuras expectativas". ${ }^{91}$ Este concepto amplio de Constitución comprende las estructuras fundamentales de la sociedad en su pluralidad. Es decir, las relaciones de los distintos grupos sociales, entre sí y con los individuos.

En lo relativo al concepto de Constitución, la postura de Häberle resulta tan amplia como la idea de cultura que adopta, aunque, desde luego, la primera es sólo un elemento o aspecto de la segunda. Esto se observa cuando propone

87 Häberle, Peter, op. cit., nota 40, p. 71.

${ }^{88}$ Häberle, Peter, op. cit., nota 4, p. 166.

89 Häberle, Peter, op. cit., nota 33, p. 5.

90 Idea fundamental en Häberle, puede leerse en distintas obras como: Häberle, Peter, op. cit., nota 40, pp. 71 y 72; Häberle, Peter, op. cit., nota 82, p. 25; Häberle, Peter, op. cit., nota 4, p. 174.

91 Häberle, Peter, op. cit., nota 4, p. 90. 
que la "Constitución viviente" 92 sea vista como la obra intelectual de los ciudadanos en constante evolución, dinámica, "en mucho grado expresión y transmisión de cultura, marco de la (re)producción y recepción culturales, y memoria de las informaciones, experiencias, vivencias, y la sabiduría culturales tradicionales". ${ }^{93}$ Con esto invita al análisis del contexto, tendiendo puentes hacia las disciplinas que tradicionalmente estudian la cultura en las dimensiones de espacio y tiempo, enunciativamente: la antropología, la sociología y la historia constitucionales, también la economía, la lingüística, la pedagogía, la ciencia política, la economía política, e incluso la teología. Una concepción de la teoría constitucional como la propuesta por Häberle demanda "muchos eslabones intermedios y la contribución de muchos científicos". ${ }^{94}$

\section{Las funciones constitucionales}

Häberle señala "un hato de diversas funciones"95 de la Constitución como cultura. Reitera que las funciones tradicionalmente reconocidas a la Constitución no se eliminan en su concepción, ${ }^{96}$ por el contrario, las considera parte de los efectos de la totalidad junto con las funciones que él propone. Entre las funciones no tradicionales, tenemos: $a$. la de concertar a los órganos del Estado y a la sociedad en general; $b$. la de servir como elemento integrador social en la pluralidad cultural; y $c$. la de propagar la virtud cívica fundada en los valores y principios superiores de la sociedad, es decir, la Constitución tiene una función pedagógica también. Como puede verse, esta asignación de funciones no elimina la función y los conceptos clásicos de la Constitución, por el contrario, los complementa para adecuarlos a las necesidades contemporáneas de la humanidad.

92 Häberle, Peter y Kotzur, Markus, op. cit., nota 3, p. 6.

93 Idem.

94 Häberle, Peter, op. cit., nota 33, p. 242.

95 Häberle, Peter, op. cit., nota 4, p. 141. Según Häberle, las funciones constitucionales tradicionalmente manejadas serían: Constituir al estado y legitimar la función de sus órganos; facultar y limitar la función de dichos órganos y servir como orden jurídico orgánico dirigido a ciertos intérpretes autorizados.

96 Ibidem, pp. 165 y 166. 


\section{La Constitución como contrato ciudadano.}

Para Häberle la Constitución puede y debe seguir siendo vista como un "contrato" o pacto político de todos con todos. En su perspectiva, el "contrato social" es solamente un modelo de pensamiento útil para explicar y justificar el esquema del Estado constitucional y no una descripción realista de los orígenes o fundamentos del Estado. ${ }^{97}$ La idea de la "mesa redonda" de los ciudadanos que propone "simboliza una comunidad política en la que muchos coexisten en pie de igualdad, unos con otros". ${ }^{98}$ El pueblo, cuyos miembros se sitúan a igual distancia y proximidad unos de otros, "se encuentra en esa condición cultural que progresa cada vez más; no se halla en el Estado de naturaleza o en el Estado de excepción al que hacen referencia las teorías desde Sieyes hasta Schmitt". ${ }^{99}$ Esta metáfora de la "mesa de negociación" simboliza la coexistencia y la convivencia de muchos en una comunidad política. El contrato es sólo un presupuesto para la construcción del proyecto. Cualquier acto constituyente contemporáneo es "visto" como un convenio socio-cultural celebrado entre ciudadanos en un status cultural propio de su momento histórico y basado en un consenso cultural fundamental, "ellos mismos se dan la Constitución". ${ }^{100}$ Esta imagen permite considerar al acto constituyente como un proceder social evolutivo y no revolucionario.

\section{La dignidad humana como premisa antropológica cultural del Estado constitucional}

La piedra sobre la que se erige el Estado constitucional en la obra de Häberle es la dignidad humana. Según nuestro autor "es el desarrollo cultural del hombre lo que lo dota de dignidad". La dignidad humana proviene o equivale a la identidad cultural (no física) de cada ser humano: es o proviene de cada individualidad cultural particular. Para sostener estas afirmaciones Häberle plantea que existe un "núcleo" de dignidad humana independiente del ámbito cultural individual. Este núcleo es constituido por el conjunto de derechos y deberes de tipo fundamental, es decir, es la suma de los valores fundamentales. Los derechos humanos, y su razonable contracara como

\footnotetext{
97 Häberle, Peter, op. cit., nota 53, pp. 72 y 73 (síntesis).

98 Häberle, Peter, op. cit., nota 82, p. 26.

99 Häberle, Peter, op. cit., nota 40, p. 95.

${ }^{100}$ Häberle, Peter, loc. cit., nota 34.
} 
deberes, "habrán de posibilitar al ser humano el convertirse en persona, el ser y continuar siendo persona". ${ }^{101}$ La identidad como persona proviene de la dignidad como ser humano. La identidad humana se forja ante todo de manera específicamente cultural. Esto es, la dignidad humana es la representación autónoma de la personalidad cultural individual. En pocas palabras, la dignidad del ser humano se identifica con su propia humanidad, y ésta es conformada culturalmente.

La idea de "igual dignidad humana del otro" hace universalizable el planteamiento de identidad de los seres humanos. Es así que "El Estado se encuentra al servicio del ser humano". ${ }^{102}$ Es entonces necesario contemplar, como lo propone nuestro autor, que "como principio jurídico, la protección de la dignidad humana es anterior no sólo al Estado, sino también al pueblo". ${ }^{103}$ "En el Estado constitucional democrático, los ciudadanos y los seres humanos al igual que su dignidad humana constituyen la "premisa antropológicocultural". Ellos se dan la Constitución a sí mismos"104 y por tanto "todas las tareas del Estado están ordenadas en función del ser humano". ${ }^{105}$ Esto sugiere una visión antropocéntrica de la Constitución. Al mismo tiempo, elimina la posibilidad de las Constituciones "otorgadas" o "pactadas". El Estado es únicamente un instrumento del ser humano y todo proceso social tiene como objetivo extremo la protección de la persona, especialmente en su parte nuclear: la dignidad.

Los derechos fundamentales no protegen a un individuo que se contrapone como extraño al Estado, sino que ellos forman parte del Estado y lo condicionan. Esta concepción diluye la idea liberal del enfrentamiento hombre-estado y, desde luego, coadyuva al "abandono de la elevación metafísica del Estado" propuesta en cualquier filosofía o manifestación totalitaria. ${ }^{106}$

101 Häberle, Peter, op. cit., nota 40, pp. 15-23, (síntesis). Para la compresión extensiva del tema conviene el estudio del capítulo 2 de la obra: Häberle, Peter, La libertad fundamental en el Estado constitucional, trad. de Carlos Ramos y Jürgen Saligmann, Perú, Universidad Católica del Perú, 1997.

102 Häberle, Peter, op. cit., nota 33, p. 174.

103 Idem.

104 Ibidem, p. 14

105 Ibidem, p. 115.

106 Häberle, Peter, op. cit., nota 53, p. 108. 


\section{Pueblo y soberanía popular}

Si la dignidad humana es la premisa básica del Estado constitucional, si "el Estado está allí a favor de los seres humanos", ${ }^{107}$ y no viceversa como ocurre en la concepción nacionalista, si el pueblo es la suma de "muchos seres humanos con dignidad propia", entonces es razonable afirmar que todo el poder dimana del pueblo y sirve al pueblo. La dignidad humana es así "la semblanza crecida y creciente de la relación entre Estado y ciudadano". ${ }^{108}$

El pueblo es el conjunto de seres humanos "portadores de derechos fundamentales, esto es, de ciudadanos", ${ }^{109}$ es el compendio o síntesis de muchos seres humanos "que se mantiene unido y organizado en su identidad y pluralidad por las relaciones culturales; es, pues, el resultado de procesos de socialización cultural que frecuentemente se prolongan por varias generaciones". ${ }^{110}$ La suma cultural de estos derechos fundamentales (humanos y ciudadanos) constituye al pueblo en sentido ideal. Es por ello que el deber jurídico fundamental del Estado es la protección y respeto de la dignidad humana. La cláusula primaria del contrato social de los ciudadanos es el cumplimiento de dicho deber. Una comprensión del Estado en este sentido, entendiendo que no existe una dignidad del Estado, que sólo existe una dignidad individual de los seres humanos, evita los peligros del desarrollo de Estados totalitarios. ${ }^{111}$

\section{El Estado culturalmente determinado}

Desde la perspectiva de Häberle, la Constitución es la cultura políticojurídica, y el Estado, un producto constitucional, hay tanto Estado como el que es constituido. Es por ello que cuando se hace referencia al Estado constitucional es inevitable que los clásicos tres elementos del Estado sean "llenados" por la cultura. En primer lugar, el territorio del Estado es culturalmente formado, un espacio cultural, no un factum brutum; es un "pedazo" de la Constitución como cultura, un espacio jurídico-cultural.

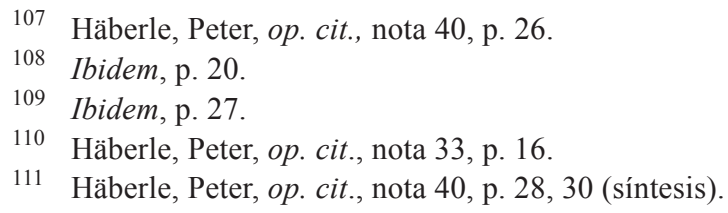


En segundo lugar, el poder del Estado se encuentra culturalmente determinado, su fundamento y límites se establecen por un producto normativo cultural. ${ }^{112} \mathrm{Y}$, finalmente, como ya vimos, el pueblo es la suma de la dignidad de todos los miembros, entendida como identidad cultural.

\section{REFERENCIAS BIBLIOGRÁFICAS}

CARBOnell, Miguel y VAladÉS, Diego (eds.), La constitucionalización de Europa, México, UNAM, Instituto de Investigaciones Jurídicas, 2004.

HÄBERLE, Peter, Verdad y Estado constitucional, trad. de Guillermo José Mañón Garibay, México, UNAM, 2006.

— Pluralismo y Constitución, trad. de Emilio Mikunda-Franco, España, Tecnos, 2002.

— y Kotzur, Markus, De la soberanía al derecho común: palabras clave para un diálogo europeo-latinoamericano, trad. de Héctor FixFierro, México, UNAM, Instituto de Investigaciones Jurídicas, 2003.

- La libertad fundamental en el Estado constitucional, trad. de Carlos Ramos y Jürgen Saligmann, Perú, Universidad Católica del Perú, 1997.

, Constitución como cultura. Artículos seleccionados para Colombia, trad. de Ana María Montoya, Colombia, Instituto de Estudios Constitucionales Carlos Restrepo Piedrahíta, Universidad del Externado de Colombia, 2002.

, El Estado constitucional, trad. de Héctor Fix-Fierro, México, UNAM, Instituto de Investigaciones Jurídicas, 2003.

- El Tribunal Constitucional como Tribunal Ciudadano. El recurso constitucional de Amparo, trad. de Joaquín Brage Camazano, México, Fundap, 2005.

, Libertad, igualdad, fraternidad, 1789 como historia, actualidad y futuro del Estado constitucional, trad. de Ignacio Gutiérrez Gutiérrez, Madrid, Trotta, 1998.

112 Häberle, Peter, op. cit., nota 33, p. 21 (síntesis). 
El federalismo y el regionalismo como forma estructural del Estado constitucional, trad. de Joaquín Brage Camazano, México, UNAM, Instituto de Investigaciones Jurídicas 2006.

Valadés, Diego (comp.), Conversaciones académicas con Peter Häberle, México, UNAM, Instituto de Investigaciones Jurídicas, 2006.

Fecha de recepción: 11 de mayo de 2011.

Fecha de dictamen: 23 de junio de 2012.

DR (C) 2012, Universidad Nacional Autónoma de México, Instituto de Investigaciones Jurídicas 